\title{
Terapia Regenerativa en Tendones y Células Madres en Medicina Equina.
}

\section{Tendon Regenerative Therapy snd Stem Cells in Equine Medicine.}

\author{
J. Ignacio Arias f. ${ }^{1}$, M.V., DSc, Carolina Beato ${ }^{2}$ \\ ${ }^{1}$ Académico en cirugía, Dpto. de Cs, Clínicas, Facultad de Cs. Vet. y Pec., Universidad de Chile \\ ${ }^{2}$ Estudiante de Doctorado, Dpto. de Cs, Clínicas, Facultad de Cs. Vet. y Pec., Universidad de Chile \\ Email: joarias@uchile.cl
}

\begin{abstract}
Resumen
Se ha realizado extensa investigación clínica con células madre en el equino, siendo una fuente de estudios vanguardistas en medicina veterinaria, así como un modelo animal excepcional. Esto ha ayudado a obtener una amplia perspectiva sobre las aplicaciones de estas técnicas en medicina humana. Aunque la mejora perceptible se han obtenido en el frente clínica, la caracterización in vitro de las células madre de equino se encuentra todavía en una etapa temprana. Para explicar los resultados favorables de la terapia de células madre clínica en el caballo, los avances se deben enfocar en la caracterización de las células madre equinas. Las lesiones tendinosas afectan frecuentemente a los caballos deportivos y representan una pérdida significativa para la industria equina. La acumulación de micro-daños dentro de la arquitectura del tendón conduce a la formación de las lesiones centrales. Los antecedentes sobre por qué estos tratamientos han sido incentivados, los datos de su uso experimental y los resultados del actual uso clínico en los caballos tratados con células madre, se presentan junto con los retos de futuro de la terapia con células madre para la comunidad veterinaria.
\end{abstract}

Palabras clave: células madre, medicina equina, regeneración, tendón, adiposo, medula ósea

\section{Introducción}

\subsection{Células madre y medicina equina}

Las células madre son células que se encuentran en el cuerpo humano y que tienen un carácter indiferenciado o "en blanco". Ellas tienen el potencial de convertirse en muchos tipos diferentes de células llevando a cabo diferentes funciones celulares.

La mayoría de las células en el cuerpo humano son diferenciadas. Eso significa que son parte de un tejido especializado que forma un órgano en particular, llevando a cabo una o varias funciones específicas. Un glóbulo rojo, por ejemplo, transporta el oxígeno, mientras que un glóbulo blanco luchar contra las enfermedades, siendo ambas parte integral del tejido llamado sangre. Estas células diferenciadas resultan del proceso de división celular de grupos de células madre totipotenciales no diferenciadas en el tiempo embrionario.

Hay dos amplias categorías de células madre dependiendo en la etapa de desarrollo de la que fueron obtenido: las células madre embrionarias (ESC) y adultas (Fortier, 2005). En contraste con ESC totipotentes, las ESC pluripotentes sólo diferencian en las tres capas germinales somáticas (meso, endo y ectodermo) ya que provienen de la masa celular interna del blastocisto (Ulloa-Montoya et al., 2005).

Las células madre adultas en cambio se aíslan a partir de diversos tejidos adultos y se consideran multipotentes, ya que sólo pueden diferenciarse en tipos de células específicas de órganos de la capa germinal de donde fueron obtenidas (Lakshmipathy and Verfaillie, 2005). 
Curiosamente, estudios recientes sugieren que las células madre adultas tienen también potencial de diferenciación en tipos celulares de linajes de tejidos diferentes del tejido de donde se obtuvieron, lo que da lugar al concepto plasticidad de las células madre (Fortier, 2005; Hoynowski et al., 2007). Como tal, existiría un escasa subpoblación de células mesenquimáticas denominadas células progenitoras adultas multipotentes (MAPC), puediendo diferenciarse no sólo en las células del linaje mesenquimal sino también en endoteliales y de endoderma (Caplan and Correa, 2011).

En la última década, las células madre mesenquimales (MSC) han recibido mucha atención dentro de la medicina veterinaria equina. El primer uso terapéutico de MSC en equinos se informó en 2003. (Burk et al., 2013) Desde entonces, la aplicación clínica de MSC ha sido una explosión de miles de caballos que han sido tratados en todo el mundo. En la actualidad, MSC's se utiliza principalmente en la medicina veterinaria para el tratamiento de enfermedades musculoesquelético en base a su capacidad de diferenciarse en diversos tejidos de origen mesodérmico. Esto está en marcado contraste con los resultados en medicina humana, donde las terapias células madre se centran principalmente en enfermedades autoinmunes, inflamatorias e isquémicas.

El considerable potencial terapéutico de las MSC's en medicina regenerativa de equinos se basada tanto en la simplicidad de su aislamiento y su capacidad para promover la regeneración de los tejidos, como también en su capacidad de evitar la formación de cicatriz patológica o exagerada mediante la modulación de la respuestas inmunes, y la regulación de la respuesta inflamatoria (Stewart and Stewart, 2011).

El caballo deportivo es un atleta de alto rendimiento y posee exigencias que superan la de un caballo de paseo. El uso diario con "repetidos microtraumas"; las exigencias máximas y las fuerzas anormales (mala conformación o incorrecto herraje) desequilibran el ciclo fisiológico de desgaste reparación.

Por lo tanto es primordial tener en cuenta que; si no se corrigen los factores que dieron origen a la lesión, ésta volverá a ocurrir. Junto con cualquier tratamiento regenerativo es necesario controlar conformación, herraje, superficie de trabajo, plan de entrenamiento y rehabilitación kinesiológica, intensidad de entrenamiento, entre otras.

El objetivo de la medicina regenerativa en equinos es cambiar el destino de una herida llevándola de la reparación y formación de una cicatriz a la regeneración del tejido y de su función original. Las células madre pueden regenerar muy bien las fracturas, pero esto no es novedoso ya que el hueso por sí solo es un tejido con gran capacidad de regenerar. Las lesiones de elección en equinos resultan ser entonces las tendinopatías y desmopatías ya que en estos tejidos se produce reparación y formación de una cicatriz siendo así difícil recuperar un tendón fuerte y elástico que permita la vuelta a la competencia.

Un ejemplo de lo anterior son las tendinitis del flexor digital superficial. La que ocurre en un 8$30 \%$ de los Fina Sangre de Carrera. Las recidivas de este tipo de lesiones al retornar al entrenamiento es muy alta: 43-93\% (Pacini et al., 2007)

De acuerdo con estudios recientes, las células madre parecen mejorar la regeneración del tendón (Crovace et al., 2010; Godwin et al., 2012). Sin embargo, todavía hay una falta de conocimiento sobre los mecanismos por la cual estas células median la reparación, así como las propiedades celulares básicas de las MSC de equinos (De Schauwer et al., 2011; Stewart and Stewart, 2011).

Para obtener los mejores resultados en la regeneración del tejido dañado es necesario combinar tres elementos:

- Matriz tridimensional donde el nuevo tejido se pueda organizar

- Células capaces de diferenciarse en fibroblastos que generen matriz extracelular en el sitio de la lesión.

- Combinación de factores de crecimiento y citoquinas que induzcan la regeneración

- Y estímulos biomecánicos adecuados para organizar la matriz producida por las células involucradas en este curación.

Estos cuatro elementos forman parte de las herramientas que se utilizan en la Ingeniería de Tejidos (Giannoudis et al., 2008) la que se define como un conjunto de conocimientos, técnicas y métodos de base biotecnológica que permiten diseñar y generar en el laboratorio sustitutos tisulares, tejidos artificiales o constructos de origen heterólogo o autólogo a partir de 
células madre y biomateriales. La ingeniería de tejidos constituye un enorme avance para la terapia celular y la medicina regenerativa siendo de vital ayuda en el desarrollo de nuevas terapias para la clínica aplicada en diferentes especies.
Para entender cómo ocupar esta herramienta es importante conocer el rol y las tres principales funciones que poseen las células Madre (Imagen 1).

Imagen 1: Principales funciones que poseen las células madre adultas.

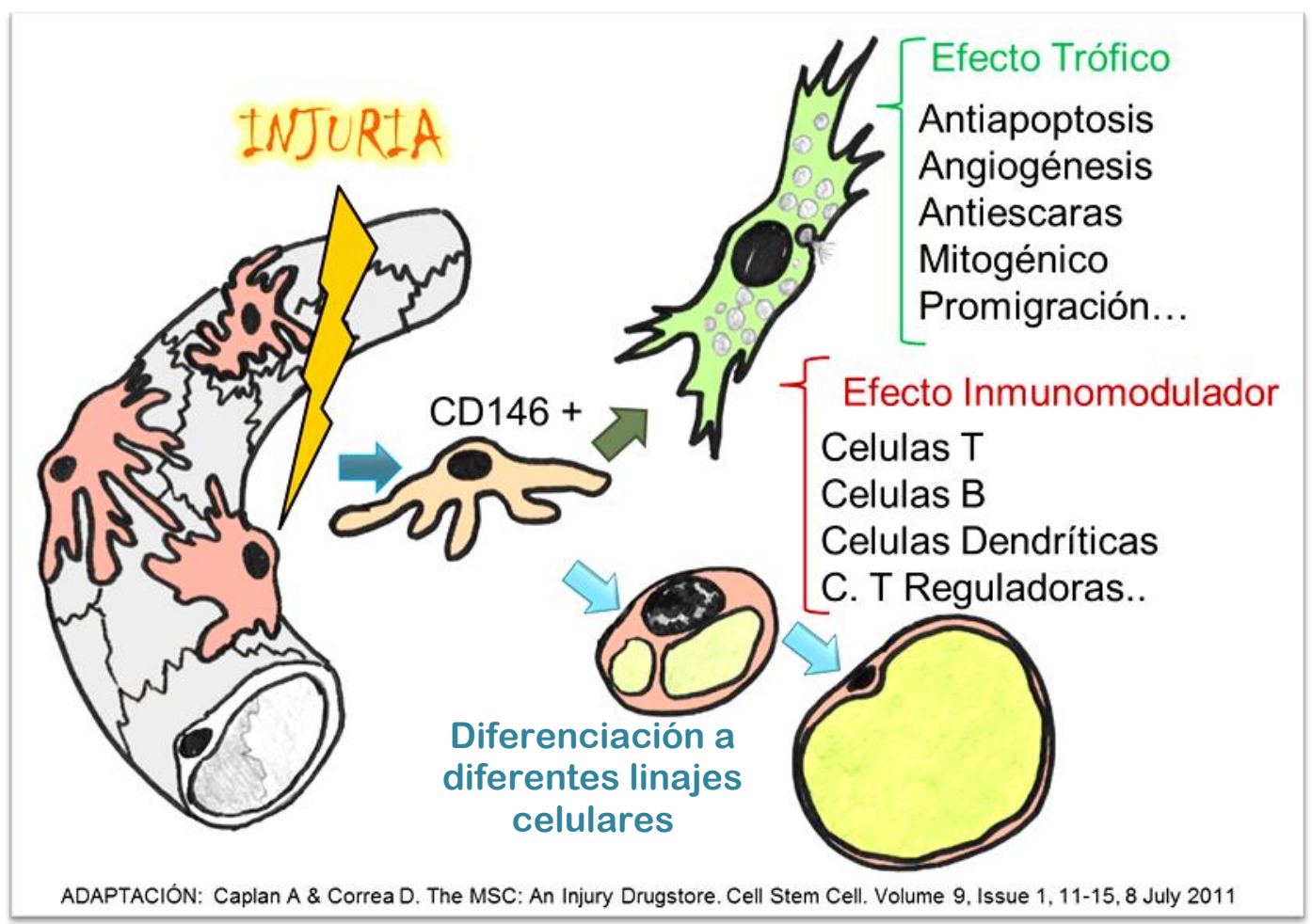

1. La primera de estas funciones, y quizás la más conocida, es la capacidad de ellas de proliferar, diferenciarse y organizarse en diferentes linajes celulares. Pudiendo de esta manera cumplir funciones de regeneración directa de tejidos.

2. La segunda función es la capacidad trófica que poseen estas células como respuesta al monitoreo que ellas realizan del ambiente en el que se encuentran. De esta manera, como una verdadera farmacia, liberan al medio intracelular factores tróficos que regulan funciones tan importantes en la reparación y regeneración como lo son estimular la proliferación celular, modular los fenómenos apoptóticos, estimular y guiar la migración celular, entre otros.

3. Finalmente también funcionan como verdaderos policías de la respuesta inmune, cumpliendo con un rol inmunomodulador de esta. Para ello genera un control sobre la actividad, entre otras, de linfocitos T y B.

\subsection{Colocación de células madre en forma exógena}

Algunos estudios hipotetizan que las células madre aplicadas al sitio de la lesión se difenciarían al tipo celular requerido y generarían la matriz extracelular requerida ellas mismas o influirían a poblaciones vecinas para hacerlo (Richardson et al., 2007). Otros, especularon que las MSC influirían mediante su acción inmunomodulador reduciendo la 
respuesta inflamatoria, favoreciendo de esta manera el procesos de curación (Peroni and Borjesson, 2011; Stewart and Stewart, 2011).

$\mathrm{Al}$ monitorear la migración de MSC's etiquetadas con GFP inyectadas en una lesión de tendón, estas adoptan una morfología similar a tenocitos y se orientan en dirección a las fuerzas biomecánicas predominantes. Sin embargo, en el mismo estudio se describe que la supervivencia o la trazabilidad de las MSC etiquetas en las lesiones del tendón era pobre ( $<5 \%$ a los 10 días y el $0,2 \%$ a los 90 días después de la inyección, respectivamente) (Guest et al., 2010), surgiendo así más preguntas relativas a la mecanismo de acción de las MSC en la regeneración del tendón.

Debe tenerse en cuenta que la mayoría, pero no todos, la investigación clínicas de diferentes grupos, utilizan productos sanguíneos autólogos, tales como el plasma, plasma rico en plaquetas (PRP), o sobrenadante de médula ósea para suspender las MSC's antes de la inyectarlas. Esto implica que factores de crecimiento autólogos, distintos de los sintetizados por las células madre inyectadas, también se transfieren al sitio de la lesión y podría contribuir a los efectos beneficiosos o adversos de la terapia celular. Estandarización de metodologías para la recolección de células, cultivo, y aplicación de estas células aportaría a aumentar la comparabilidad entre diferentes estudios (Burk et al., 2013). Muchos de estos estudios han mostrado efectos favorables sobre la organización del tejido, la composición, y la mecánica de las MSC-implantadas en tendones y ligamentos (Butler et al., 2008; Crovace et al., 2010; Kovacevic and Rodeo, 2008; Schnabel et al., 2009).

Por otra parte, otros estudios se han focalizado a mejorar la cosecha y los procedimientos de aislamiento de MSC equinas de varios fuentes de tejido (Bourzac et al., 2010; Corradetti et al., 2011; Kasashima et al., 2011; Koch et al., 2009b; Taylor and Clegg, 2011), sin embargo, no existen protocolos estandarizados que se hayan acordado. Estos y otros estudios varían en diseño experimental con respecto al número de MSC implantadas (0,5 a $10 \times 106)$, vehículo para suspensión (plasma, solución salina tamponada con fosfato, sobrenadante de médula ósea), y el tiempo de inyección transcurrido después de que la lesión se ha instaurado (hasta 2 semanas) (Butler et al., 2008; Crovace et al., 2010; Kovacevic and Rodeo, 2008; Schnabel et al., 2009).

Además, la investigación con células madre equina se beneficiarían considerablemente de una caracterización más exacta de los tipos de células utilizados en los estudios clínicos.

Un ejemplo de esta falta de esta falta de diseño experimental, el pionero en medicina regenerativa Dr. Doug Hertel (DVM) de Alamo
Pintado- California aspiró médula ósea del esternón de 100 caballos y las inyectó en lesiones de ligamentos suspensorios, obteniendo buenos resultados. La desventaja de esta técnica es que hay pocas MSC, pero es muy rica en factores de crecimiento. Por lo anterior se requieren inyectar grandes volúmenes de médula ósea para lograr una buena cantidad de MSC's (30-50 ml) causando daño mecánico local por aumento de la presión entre los tejidos. Por otra parte, los altos niveles de TGF- $\beta 1$ (transforming growth factor) presentes en este aspirado producen excesiva cantidad de tejido cicatrizal (Herthel, 2001).

En una series de casos, no-ciegos, nocontrolados, realizados por Godwin y col. aplicaron sobre 141 tendones equinos, MSC cultivadas derivados de medula ósea y se les hizo seguimiento por al menos 3 años. Los Autores reportaron una disminución significativa en la tasa de repetición de la lesión en caballos de carreras "National Hunt", pero no así al ser usado en caballos purasangre de carrera de pista plana al compararlo con registros históricos usando tratamientos tradicionales (23\% a $66 \%)$.

En el mercado nacional se ofrece el servicio intraoperatorio para la obtención de células de la fracción del estroma vascular de tejido adiposo (AD$\mathrm{SVF}$ ). Esta fracción es producto de la digestión enzimática del tejido adiposo extirpado quirúrgicamente y de la filtración y centrifugado sucesivo de la misma, obteniéndose de esta manera un pellet rico en preadipocitos, MSC's, células progenitoras endoteliales, células $\mathrm{T}$, células $\mathrm{B}$, mastocitos y macrófagos del tejido adiposo (Fig. 2) (Godwin et al., 2012; Riordan et al., 2009).

Para aplicarlas las AD-SVF simplemente se aíslan y se se inyecta en el paciente sin una etapa de cultivo de células. En comparación con MSC aisladas y cultivadas, esta técnica tiene la ventaja de que suministran en un periodo de tiempo corto (Intraoperatorio) un producto inyectable. Debe recordarse que, aunque hay un gran número de células nucleadas recuperado del pellet, el producto de digestión del tejido adiposo posee sólo un pequeño porcentaje de las células nucleadas presentes son MSC's. En los seres humanos, solo el $0,7 \%$ a $5 \%$ de las células nucleadas de la AD-SVF son las células madre (Jurgens et al., 2008).

Esta metodología se está usando desde ya un tiempo en forma clínica en equinos, pero sin ninguna evidencia científico-clínica, ya que las publicaciones encontradas solo mencionan su uso a nivel experimental en modelo tendón de conejos (Behfar et al., 2011; Behfar et al., 2012).

Además del resultado clínico general de estos estudios que hablan de una mejoría clínica de los pacientes, estos estudios también mostraron que relesiones tienden a aparecer con menos frecuencia 
cuando se aplican una mayor cantidad de MSC (por lo menos alrededor de 1 x $10^{7} \mathrm{MSC}$ ) (Godwin et al., 2012; Pacini et al., 2007)(8,55), o cuando los pacientes son más jóvenes (Burk and Brehm, 2011; Godwin et al., 2012)(8,56) o cuando el tiempo entre la ocurrencia de la lesión y la aplicación de células es más corto (Godwin et al., 2012)(8). Además, la disciplina deportivo para el que se utiliza el caballo parece tener una gran influencia en el éxito del tratamiento (Godwin et al., 2012)(8,56).

Sin embargo, hay que señalar que el tratamiento con MSC no sustituye o acorta la rehabilitación estándar, pero es más bien un tratamiento adicional que mejora los resultados.

Experimental en estudios in vivo permiten llegar a la hipótesis de que esta mejora podría ser debida principalmente al hecho de que las MSC's mejorar la organización estructural del tejido reparado.

\subsection{Obtención y uso de células madre de origen adiposo (adsc)}

El momento ideal para el uso de células madre en una lesión tendinosa se ha descrito que debiese realizarse después de la etapa inflamatoria y antes de la de remodelación. Entre los 7 y 28 días post lesión (etapa regenerativa), antes que el organismo "apague las señales" y comience a formar una cicatriz (Burk and Brehm, 2011).

Si se implantan una buena cantidad de células, éstas, atraerán otras, modulan la reparación e inflamación, formando neovascularización y tejido tendinoso nuevo.

Los tratamientos convencionales para tendinitis, apuntan a mejorar la "reparación": desde el reposo (6 a 15 meses); ejercicio controlado, frío, antiinflamatorios, fisioterapia, splitting, desmotomía del ligamento frenador distal, cáusticos, etc.

El implante intralesional de células madre apunta a la "regeneración", no solo a la reparación. Es decir, lograr tejido con la misma estructura y función del tejido original.

En el 2002 Robert Harman (California) comienzan a tratar lesiones en equinos con células madre de tejido adiposo (Riordan et al., 2009). Se obtiene un concentrado de células madre a partir de tejido adiposo subcutáneo equino. Hay gran cantidad de células madre en el tejido adiposo: 1 de cada 50 células (2\%). No se requiere cultivarlas para expandirlas, porque hay suficientes células en la muestra para poder ser implantadas hasta en el mismo día.

Ventajas del tejido adiposo:

- Gran número de células madres.

- Son muy accesibles en grandes cantidades con una mínima morbilidad.

- La muestra es fácil de extraer

- No es un tejido imprescindible para el animal.

- Se implantan en su estado natural dentro del tejido dañado para regenerarlo.

- Estas células tienen pocas barreras prácticas, éticas e inmunológicas para su aplicación clínica.

\subsubsection{Obtención de la muestra:}

La muestra de tejido adiposo para obtención de células madre se realiza con el caballo en pie, bajo sedación y luego de tricotomía y anestesia local, se realiza una incisión en piel (de la región del cuello o de área glútea). Se separa la piel del tejido adiposo subcutáneo y se procede a extraer entre 15 a 20 gramos de grasa y se colocan en un medio de cultivo estéril para su traslado al laboratorio.

\subsubsection{Implante intralesional:}

Una vez que la muestra es procesada mediante digestión enzimática y sucesivos centrifugados del tejido, se obtiene un concentrado estéril de células y restos celulares denominado fracción del estroma vascular de tejido adiposo (AD-SVF) (Imagen 2) que es utilizada, en la clínica diaria, en forma directa en la región afectada para el tratamiento de patologías tendinosas, siendo vehiculizada con plasma autólogo o plasma rico en plaquetas (PRP) (Pacini et al., 2007). Sin embargo, para obtener una población más homogenia de células madre, esta AD-SVF se cultiva por 1 o 2 semanas para obtener un cultivo primario de células madres (ADSC). 
Imagen 2: Resultado del proceso de digestión enzimática y sucesivos centrifugados del tejido adiposo equino. (SVF) concentrado estéril de células y restos celulares denominado fracción del estroma vascular de tejido adiposo

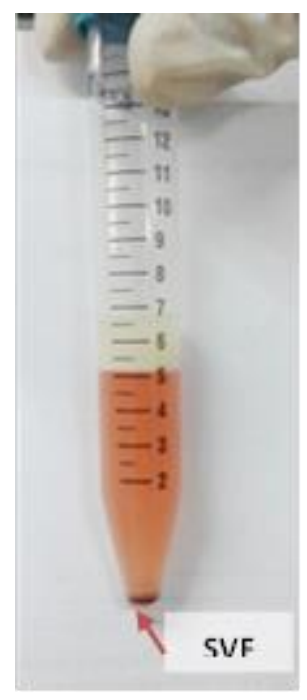

Bajo sedación y con anestesia local, se realiza tricotomía del sitio de inyección y con guía ecográfica y aguja, se han colocado en forma intralesional estos dos tipos de extractos celulares. Se han utilizado además antiinflamatorios no esteroides, hielo, vendaje compresivo y DMSO que se describe empíricamente que no dañan a las células y reducen el edema. Se dice además que no es conveniente suministrar corticoesteroides porque retardarían la cicatrización.

Las células madre se ha descrito que pueden se inyectadas en forma endovenosa y migraran al sitio lesionado, ya que son atraídas por las señales que emite la inflamación o daño.

En el caso de los tendones, el tejido es poco vascularizado por lo que esta característica de búsqueda y migración a tejido afectado, no se aplica. Para superar este inconveniente es que se implantan en forma intralesional las células en lugar de inyectarlas endovenosas y que migren solas. Se describe que estas MSC se suspenden en suero autólogo para su inyección (Pacini et al., 2007), lo que suma más variable de al analizar el contenido de factores moduladores del crecimiento e inflamación presentes en ese suero.

La terapia con células madre no provoca una recuperación más rápida, no se acortan los tiempos de recuperación. La ventaja de esta terapia es tener un tendón mucho mejor estructurado a nivel histológico, más elástico y con menor riesgo de volver a lesionarse.

\section{Conclusiones}

La investigación clínica con células madre en el caballo, ha llevado a muchos resultados prometedores pero poco concluyentes por motivos de error en el diseño del experimento (Koch et al., 2009a). Por esto, aún se requiere más investigación in vivo e in vitro para obtener un conocimiento más profundo $\mathrm{y}$ acabado de la biología de células madre equinas y los mecanismos subyacentes a los efectos regeneradores de estas. Las metodologías que entregan la medicina regenerativa y las células madre son prometedoras, pero deben de ser consideradas como una herramienta más de tratamiento en ciertos casos de lesiones tendineas. Para esto los futuros trabajos de investigación deben apuntar a protocolizar el material y métodos usados para hacer los resultados comparables. La homogeneidad de la herramienta terapéutica que puede surgir del uso de las MSC es fundamental para obtener resultados validables y medianamente repetibles en casos similares.

El uso de extractos celulares heterogéneos o suplementos con factores moduladores del crecimiento e inflamación, como lo es el plasma rico en plaquetas o suero autólogo, genera nuevas inconstancias que hacen que la variabilidad del resultado sea inesperado.

Agradecimientos: Al proyecto de investigación FIV DI-FAVET 2012, 


\section{Referencias}

1. Behfar, M., Sarrafzadeh-Rezaei, F., Hobbenaghi, R., Delirezh, N., DalirNaghadeh, B., 2011. Adipose-derived stromal vascular fraction improves tendon healing in rabbits. Chinese journal of traumatology $=$ Zhonghua chuang shang za zhi / Chinese Medical Association 14, 329-335.

2. Behfar, M., Sarrafzadeh-Rezaei, F., Hobbenaghi, R., Delirezh, N., DalirNaghadeh, B., Behfar, M., SarrafzadehRezaei, F., Hobbenaghi, R., Delirezh, N., Dalir-Naghadeh, B., 2012. Enhanced mechanical properties of rabbit flexor tendons in response to intratendinous injection of adipose derived stromal vascular fraction. Adipose-derived stromal vascular fraction improves tendon healing in rabbits. Current stem cell research \& therapy 7, 173178.

3. Bourzac, C., Smith, L.C., Vincent, P., Beauchamp, G., Lavoie, J.P., Laverty, S., 2010. Isolation of equine bone marrowderived mesenchymal stem cells: a comparison between three protocols. Equine Vet J 42, 519-527.

4. Burk, J., Badylak, S.F., Kelly, J., Brehm, W., 2013. Equine cellular therapy-from stall to bench to bedside? Cytometry Part A 83A, 103-113.

5. Burk, J., Brehm, W., 2011. Stem cell therapy of tendon injuries - clinical outcome in 98 cases. Pferdeheilkunde fundus 27, 153-161.

6. Butler, D.L., Juncosa-Melvin, N., Boivin, G.P., Galloway, M.T., Shearn, J.T., Gooch, C., Awad, H., 2008. Functional tissue engineering for tendon repair: A multidisciplinary strategy using mesenchymal stem cells, bioscaffolds, and mechanical stimulation. J Orthop Res 26, 1-9.
7. Caplan, Arnold I., Correa, D., 2011. The MSC: An Injury Drugstore. Cell Stem Cell 9, 11-15.

8. Corradetti, B., Lange-Consiglio, A., Barucca, M., Cremonesi, F., Bizzaro, D., 2011. Sizesieved subpopulations of mesenchymal stem cells from intervascular and perivascular equine umbilical cord matrix. Cell Prolif 44, 330-342.

9. Crovace, A., Lacitignola, L., Rossi, G., Francioso, E., 2010. Histological and immunohistochemical evaluation of autologous cultured bone marrow mesenchymal stem cells and bone marrow mononucleated cells in collagenase-induced tendinitis of equine superficial digital flexor tendon. Veterinary medicine international 2010, 250978.

10. De Schauwer, C., Meyer, E., Van de Walle, G.R., Van Soom, A., 2011. Markers of stemness in equine mesenchymal stem cells: a plea for uniformity. Theriogenology 75, 1431-1443.

11. Fortier, L.A., 2005. Stem cells: classifications, controversies, and clinical applications. Veterinary surgery : VS 34, 415423.

12. Giannoudis, P.V., Einhorn, T.A., Schmidmaier, G., Marsh, D., 2008. The diamond concept--open questions. Injury 39 Suppl 2, S5-8.

13. Godwin, E.E., Young, N.J., Dudhia, J., Beamish, I.C., Smith, R.K., 2012. Implantation of bone marrow-derived mesenchymal stem cells demonstrates improved outcome in horses with overstrain injury of the superficial digital flexor tendon. Equine Vet J 44, 25-32.

14. Guest, D.J., Smith, M.R.W., Allen, W.R., 2010. Equine embryonic stem-like cells and 
mesenchymal stromal cells have different survival rates and migration patterns following their injection into damaged superficial digital flexor tendon. Equine Vet $\mathrm{J}$ 42, 636-642.

15. Herthel, D.J., 2001. Enhanced suspensory ligament healing in 100 horses by stem cells and other bone marrow components. . Proc. Am. Ass. Equine Practnrs. 47, 319-321.

16. Hoynowski, S.M., Fry, M.M., Gardner, B.M., Leming, M.T., Tucker, J.R., Black, L., Sand, T., Mitchell, K.E., 2007. Characterization and differentiation of equine umbilical cordderived matrix cells. Biochem Biophys Res Commun 362, 347-353.

17. Jurgens, W.J., Oedayrajsingh-Varma, M.J., Helder, M.N., Zandiehdoulabi, B., Schouten, T.E., Kuik, D.J., Ritt, M.J., van Milligen, F.J., 2008. Effect of tissue-harvesting site on yield of stem cells derived from adipose tissue: implications for cell-based therapies. Cell and tissue research 332, 415-426.

18. Kasashima, Y., Ueno, T., Tomita, A., Goodship, A.E., Smith, R.K., 2011. Optimisation of bone marrow aspiration from the equine sternum for the safe recovery of mesenchymal stem cells. Equine Vet $\mathbf{J} 43$, 288-294.

19. Koch, T.G., Berg, L.C., Betts, D.H., 2009a. Current and future regenerative medicine principles, concepts, and therapeutic use of stem cell therapy and tissue engineering in equine medicine. Can Vet J 50, 155-165.

20. Koch, T.G., Thomsen, P.D., Betts, D.H., 2009b. Improved isolation protocol for equine cord blood-derived mesenchymal stromal cells. Cytotherapy 11, 443-447.

21. Kovacevic, D., Rodeo, S.A., 2008. Biological augmentation of rotator cuff tendon repair. Clin Orthop Relat Res 466, 622-633.

22. Lakshmipathy, U., Verfaillie, C., 2005. Stem cell plasticity. Blood Reviews 19, 29-38.
23. Pacini, S., Spinabella, S., Trombi, L., Fazzi, R., Galimberti, S., Dini, F., Carlucci, F., Petrini, M., 2007. Suspension of bone marrow-derived undifferentiated mesenchymal stromal cells for repair of superficial digital flexor tendon in race horses. Tissue engineering 13, 2949-2955.

24. Peroni, J.F., Borjesson, D.L., 2011. AntiInflammatory and Immunomodulatory Activities of Stem Cells. Veterinary Clinics of North America: Equine Practice 27, 351362.

25. Richardson, L.E., Dudhia, J., Clegg, P.D., Smith, R., 2007. Stem cells in veterinary medicine - attempts at regenerating equine tendon after injury. Trends Biotechnol 25, 409-416.

26. Riordan, N.H., Ichim, T.E., Min, W.P., Wang, H., Solano, F., Lara, F., Alfaro, M., Rodriguez, J.P., Harman, R.J., Patel, A.N., Murphy, M.P., Lee, R.R., Minev, B., 2009. Non-expanded adipose stromal vascular fraction cell therapy for multiple sclerosis. $\mathrm{J}$ Transl Med 7, 29.

27. Schnabel, L.V., Lynch, M.E., van der Meulen, M.C.H., Yeager, A.E., Kornatowski, M.A., Nixon, A.J., 2009. Mesenchymal stem cells and insulin-like growth factor-I geneenhanced mesenchymal stem cells improve structural aspects of healing in equine flexor digitorum superficialis tendons. Journal of Orthopaedic Research 27, 1392-1398.

28. Stewart, M.C., Stewart, A.A., 2011. Mesenchymal Stem Cells: Characteristics, Sources, and Mechanisms of Action. Veterinary Clinics of North America: Equine Practice 27, 243-261.

29. Taylor, S.E., Clegg, P.D., 2011. Collection and propagation methods for mesenchymal stromal cells. Vet Clin North Am Equine Pract 27, 263-274. 
30. Ulloa-Montoya, F., Verfaillie, C.M., Hu, W.S., 2005. Culture systems for pluripotent stem cells. Journal of Bioscience and Bioengineering 100, 12-27. 